\title{
HUNTER GATHERER
}

\author{
Craig WHITTET ${ }^{1}$, Mark HALE ${ }^{1}$, Monica CALLAGHAN ${ }^{2}$ and Lola SANCHEZ-JAUREGUI ${ }^{2}$ \\ ${ }^{1}$ Glasgow School of Art \\ 2University of Glasgow
}

\begin{abstract}
This paper will explain the process and background of the Product Design Engineering (PDE) undergraduate project in collaboration with University of Glasgow's Hunterian Museum. The project asked students to actively engage with collections from The Hunterian, Scotland's oldest public museum and home to one of the finest university collections in the world. At over 200 years old, The Hunterian is one of Scotland's most important cultural assets and has been recognised as a Collection of National Significance.

Throughout the project, students benefited from engagement with a number of museum professionals to support their experiential learning journey using collections [1]. Hunterian founder, Dr William Hunter's (1718-1783) education in Scotland during the Age of Enlightenment had taught him the empirical method and the importance of learning through observation and practical experience, which was the basis for the initial project investigation. Students selected items from the collection and completed the 'Ways of Looking' visual examination with the aim of understanding the context and significance of the artefacts.

The next phase set students the challenge of reinterpreting their chosen object and positioning it as a future vision for a possible Hunter Quincentenary Exhibition, 500 years from the birth of Hunter in the year 2218. This future positioning posed a number of discussion topics, including, but not limited to; society, technology and ethics. These topics were to be considered as students developed their visions of the future.
\end{abstract}

Keywords: Museum, product design engineering, cultural engagement, future vision

\section{INTRODUCTION}

The paper will present examples of active learning though project engagement, student investigation, concept development and exhibition. It will also provide an evaluation and analysis from PDE and Hunterian staff. Explore next phases of collaborations and present visions of future engagement that will be of potential value to the cultural and heritage communities.

The devastating fire at the Mackintosh building in 2018 created a major relocation issue for the School of Design. The decision was made to run a project that would not require GSA studio access for the initial 3 weeks of the Y2 experience. PDE students only attend GSA 1 day a week, therefore finding a suitable venue and project would be less demanding than week long project schedules. There was also an opportunity to select a venue that would demonstrate how space can enhance the creative learning process and encourage cultural engagement, while linking with a partner with clear educational aims. The Hunterian provided an ideal partnership and having access to world class facilities that would encourage students to interact with objects and artefacts would prove to be an excellent experience. It was clear that The Hunterian continues in its Age of Enlightenment mission to be a central resource for research and teaching in the arts, humanities and natural and medical sciences.

\section{THE HUNTERIAN}

\subsection{Engagement}

The Hunterian is one of the leading university museums in the world and its collections have been recognised as a Collection of National Significance. However, even though it is a central feature of the University of Glasgow campus it is concerning how many of the Y2 PDE students had not visited or 


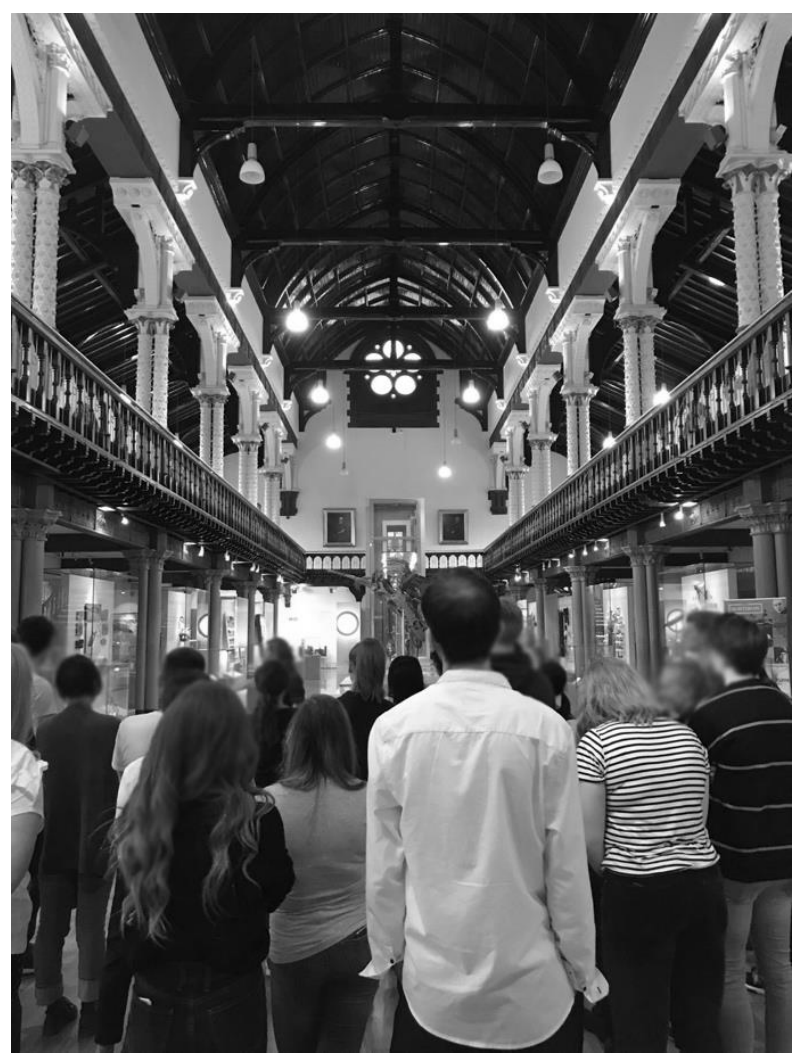

Figure 1. Students visiting the Hunterian Museum

experienced what The Hunterian has to offer. Not only would this project encourage access to the collection, it would also provide students with the opportunity to explore a major new exhibition at The Hunterian - William Hunter and the Anatomy of the Modern Museum. The exhibition celebrated Dr William Hunter's Tercentenary - 300 years since the birth of Hunterian founder. Therefore, accessing this collection was central to the project and how the artefacts would influence and inspire the 2218 future visions.

\subsection{University Museums in the 21st Century}

A recent report on the mission and character of campus museums in the $21^{\text {st }}$ Century urged these institutions to address and identify the challenges that university museums are facing both adapting to and influencing a new and still-shifting cultural landscape [2]. The report drew attention to the ways in which academic museums are affected by the profound changes sweeping through higher education, including the advent of new modes of teaching-learning and the erosion of established disciplinary boundaries.

The Hunterian, embrace this challenge with a strong commitment to foster interdisciplinary modes of inquiry and innovative pedagogical approaches to create powerful experiences that help prepare a more globally competent student. The collections and exhibits are a tremendous resource, add to that a capacity to work across disciplines with faculty and students and this would play a central role in meeting one of the most dynamic challenges confronting the academia today.

The question then is, how can museums nurture global competence through deliberate engagement with educators and students in formal educational settings and with contemporary global issues in mind?

Through collaborations like "Hunter Gatherer", The Hunterian seeks to answer this, developing capacity and creating models that advance this goal. Collaborative projects like this can help nurture and contribute to build student's skills, educating $21^{\text {st }}$ Century students to be critical viewers, critical producers of visual culture and critical developers of future concepts and scenarios. 


\section{HUNTER GATHERERS}

The project began with a series of discussions, which was a move away from the traditional launching of a brief. We asked a number of questions to provoke thoughts and discussion, such as what do we collect these days? Do we collect more digital data than physical artefacts? What will we collect in the future? Will it be more of the virtual and less of the physical experience? Will we even possess a physical presence in the future? There was also a very valuable discussion focusing on paying for digital data that can be accessed through a variety of physical devices and interfaces. The students also raised the aspect of providing others (sometimes unknowingly) with our data; this can be biological, location, thoughts, identity etc.

The first phase was visiting the Hunterian and using their educational tool 'Ways of Looking' as a starting point for visual analysis and recording. A student had to select at least two objects to review and analyse. The main elements of investigation of 'Ways of Looking' include:

\subsection{An Individual Response}

Our responses to looking at objects, whether they are pictures in a gallery or artefacts in a museum, are affected by who we are as individuals. Every person relates differently to things in their environment. Individuals have their own perceptions and views on what their eyes see, like Dr Hanneke Grootenboer eloquently expressed it: "Artworks do not belong to the period in which they were produced but live a life in front of constantly changing audiences... in light of its biography an artwork it is as much part of history as it is of our present day" [3]. When we look at objects we must consider what our eyes actually see, and not what we think we are looking at. Using what we see, our reactions, memories and existing knowledge can help us to build a greater picture of the objects we engage with.

\subsection{What you see}

We can see artefacts in terms of what we think it is. We may discover more by breaking down what we see into distinct areas such as content, theme, period, title, mood, or the type of work it is. We can compare and contrast different examples to learn more. Studying similarities and differences as well as our own preferences, opinions, responses and reactions can all help increase appreciation and understanding of art, design and engineering.

\subsection{What is it?}

Different objects and forms have their own individual qualities. Art and design can be used as a visual language which can take a number of forms, including drawing, painting, sculpture, print, film, video, photograph, product or other design. How art and design can influence how we see or understand the work. If we look at formal qualities, such as composition, line, shape, colour, tone, texture, space and mass, as well as appropriateness material and process, we can begin to learn a little more.

\subsection{Linking Art \& Design Engineering to a wider context}

To investigate more about a work of art and/or design, we can look at by whom, where, what, why and when it was made. Perhaps by looking at the social and historical context of the work, we can discover more. Linking or contrasting present day context may too give us a different interpretation.

In addition to the 'Ways of Looking' methodology, this brief also asked students to consider what was the current day example of the objects. If they didn't exist, they had to specify and document a parallel product/artefact.

The second phase of the project was a visit to The Hunterian Collection Study Centre at Kelvin Hall, an exciting new centre of cultural excellence providing access to collections, temporary displays, teaching and research. This was a major aspect of the project as students actually had the opportunity to explore the value of object-based learning [4] by physically holding and experiencing a diversity of the museum's manmade and natural artefacts ranging from minerals, Roman pottery to dinosaur poo! 


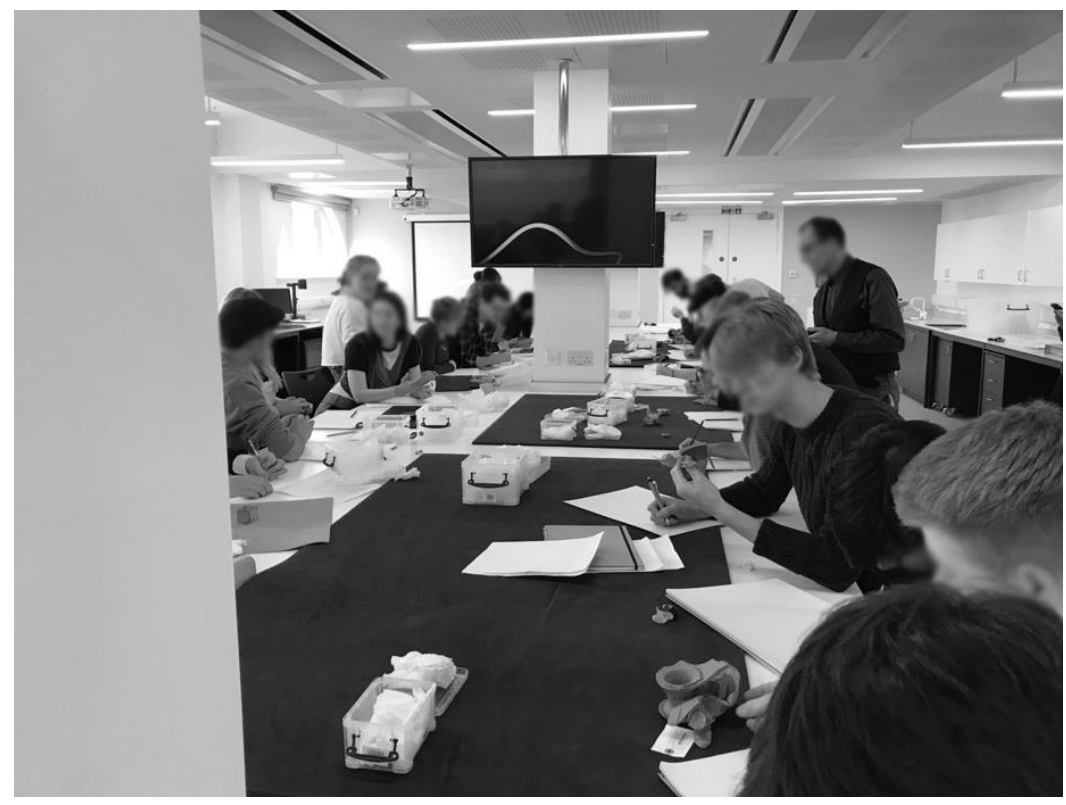

Figure 2. Students engaging with the Ways of Looking, Hunterian Handling Rooms

\section{WILLIAM HUNTER AND THE ANATOMY OF THE MODERN MUSEUM}

A significant part of this project was a tour around the William Hunter Tercentenary exhibition, The Anatomy of the Modern Museum by the lead curator. The exhibition not only offered a critical examination of William Hunter's life, research and career, but also explored the nature of his 'encyclopaedic' museum, considering the underlying ideas that connected art, objects, anatomical specimens or books to recover the intellectual vision of a man that did not distinguish boundaries between art and science.

The tour provided an overview of the museum and context, and a discussion about how we interact, experience objects and artefacts in a museum context. It was also during this visit that the students were made aware of Hunter's background and approach. His education in Scotland had taught him the importance of learning through observation and practical experience, rather than through texts written by even the best practitioners [4]. This insight is of particular relevance to PDE, primarily due to the joint nature of the collaborative delivery. In essence, the theory of engineering science is taught at the university and the theory of design engineering is applied and experienced at the Glasgow School of Art.

\section{FUTURE HUNTERS}

The next phase in the project would ask students to consider the future context of The Hunterian Collection. Discussions with the students explored how we are now facing unprecedented change in how we interact and access the world around us, and beyond. It was encouraging to witness discussions where students started to explore the ethics of collecting by asking if Hunter would have collected and preserved anatomical specimens, if he had access to ultrasound scanners and digital interactive models of species? These discussions, and others fuelled the project task of exploring what users in the year 2218 , the 500th Anniversary of Hunter's birth would experience. Students were also exploring the notion [5] that medical science will provide tools and treatments that will enable people born in the noughties to live in excess of a thousand years. The idea that this group of students may be around to witness Hunter's 500th birthday is possibly more realistic than you can imagine. 


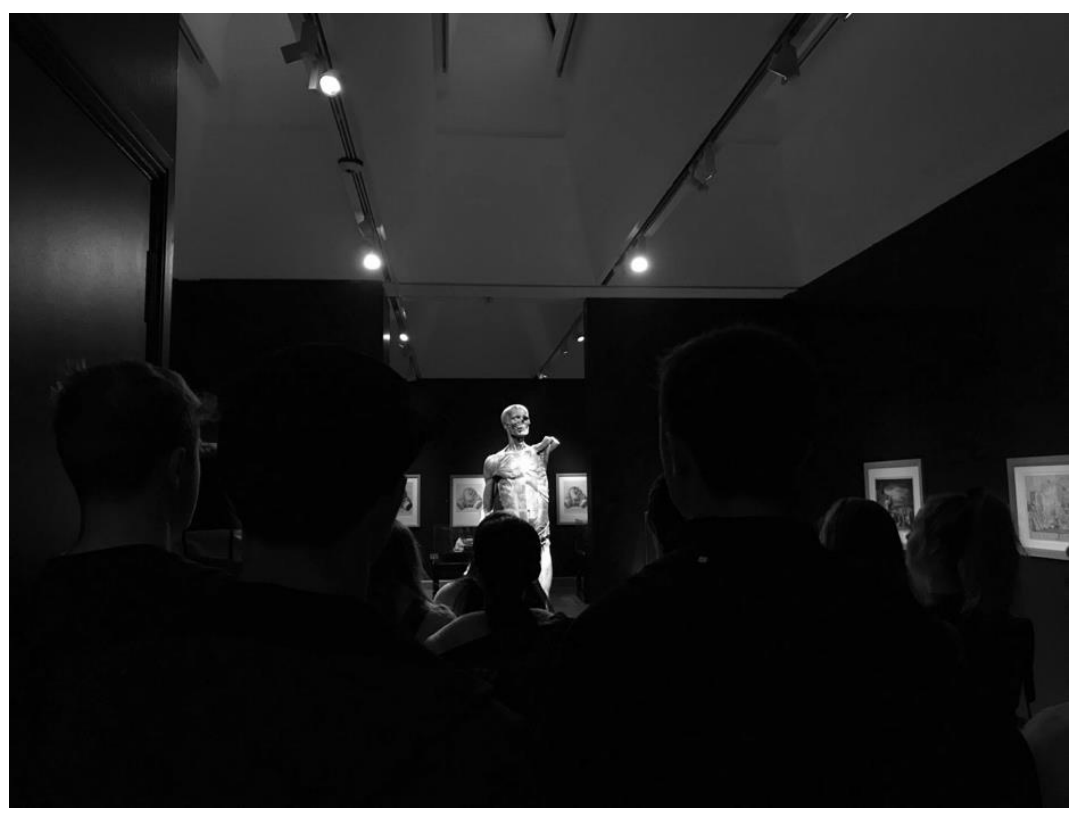

Figure 3. Students visiting The Anatomy of the Modern Museum Exhibition

The students were asked what the artefacts that they initially looked at for this brief would be in 2218 ? This did raise a valuable debate amongst the group as it is quite possible that the objects and experiences that they are responsible for in their careers as product design engineers will still have a place, and potentially, still be in use in 2218. An example of this that could be consider is the collection of Roman Artefacts in the Hunterian. Using this collection as inspiration, the students started to consider the idea of frontiers. Some product concepts started to explore what the frontier will be in 200 years' time? Will frontiers be physical, digital, or it may be another experience that has yet to developed and defined? Due to the time constraints of the project, the students had to select one of the artefacts and then develop 3 concepts for their 2218 vision. These initial concepts were then presented at an interim stage, evaluated and then a chosen concept was selected to be developed further. The challenge with this future approach is that we do not have any answers, but at least we have access to a collection that displays and promotes how society, economy, ethics, medical science and communication have developed. Therefore, the Hunterian collection played a major role in the back casting of concepts and future scenarios.

The evaluation stage of the project provided another opportunity to view and consider the initial objects that the students had selected during the 'Ways of Looking' stage of the process. There didn't appear to be a particular theme, but students were drawn towards man-made objects. This may be in part due to their interests, background and items that they felt would provide a good basis for the future visions. This was also a point to discuss the dialogue and engagement with the collection and artefacts with The Hunterians education and curatorial professionals. This was a pivotal discussion and significant in the development of future collaborations and the next phase.

\section{CONCLUSIONS \& OBJECTS OF RESEARCH}

As noted above, the next phase of this project is of particular value to both the Hunterian and PDE. The Hunterian were very supportive of how the project enabled a new approach to cultural engagement, interacting and experiencing the collection. This approach of experiential learning is heavily linked with Hunter's Enlightenment philosophy. Building on the collaborative and explorative nature of the partnership between The Hunterian and PDE, there are plans to build on the project and create an innovative new display in 2019, entitled Objects of Research. The selected concepts from the Hunter Gatherer project will be digitised and 3D printed at an appropriate scale. The drawings and concept development work will also feature, and this will provide an overview of the student's engagement. The actual artefact that was initially observed and analysed by the student will also be part of this exhibition. This will not only provide a context for the exhibit but will also encourage visitors to consider what their visions of the 2218 future could be. This approach to developing an exhibition is responding to, on one hand, to the need for solutions to be generated for a growing market. Recent listings in the Museums 
Association's Directory of Suppliers and Consultants detail more than 150 different types of business, and recent reports of the sector have stressed how "innovative approaches to all aspects of interpretation and display are important growth areas... Museum design is moving into a new era that is far more exciting and the design, use of spaces and creation of environments is now being considered a lot more" [6]. On the other hand, this approach to developing an exhibition responds to the significant expanse of the "Transhistorical exhibitions" within the curatorial world. A range of curatorial efforts that have emerged over the last decades in which objects and artefacts from various periods and cultural contexts are combined in the display to question traditional museological notions. This curatorial exercise proposes a way to look at the past via the present (and vice versa) and has enormous potential for new ways of interpreting and learning [7].

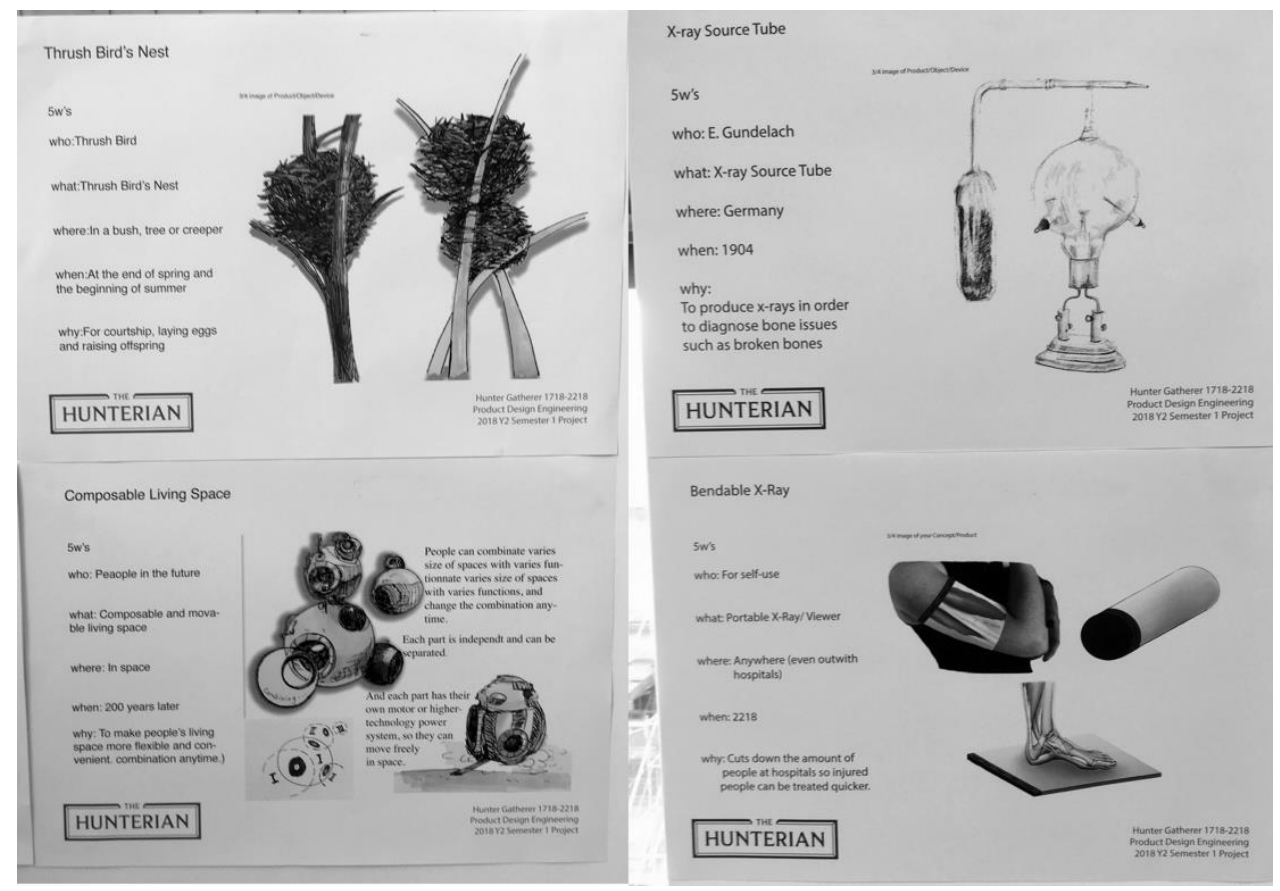

Figure 4. Examples of 2218 Future Visions

It is hoped that this project will continue to be a feature of the PDE Y2 experience in future years and further collaboration with The Hunterian.

\section{REFERENCES}

[1] Kolb A.Y. and Kolb D.A. "Learning Styles and Learning Spaces: Enhancing Experiential Learning in Higher Education.” Academy of Management Learning \& Education, vol. 4, no. 2, 2005, pp. 193-212. JSTOR, www.jstor.org/stable/40214287.

[2] Shapiro T., Linett P., Farrell B. and Anderson W. Campus art museums in the 21st. Century: A conversation, Cultural Policy Centre at the University of Chicago, 2012.

[3] From an interview with Hanneke Grooteboer "(Re) Discovering Art History's Philosophical Foundations" in E. Wittocx, A. Demeester, P. Carpreau, M. Buhler and X. Kaskens (ed.) The Transhistorical Museum. Mapping the Field. Valiz, Amsterdam 2018, p. 40.

[4] The Hunterian. William Hunter and the Anatomy of the Modern Museum, Exhibition Guide, 2018.

[5] Ray Kurzweil. https://www.businessinsider.com/googles-chief-futurist-thinks-we-could-startliving-forever-by-2029-2016-4?r=US\&IR=T.

[6] Museums Association's Directory of Suppliers.

[7] From the Introduction section in E. Wittocx, A. Demeester, P. Carpreau, M. Buhler and X. Kaskens (ed.) The Transhistorical Museum. Mapping the Field. Valiz, Amsterdam 2018, p. 13. 